\title{
Seroprevalence of TORCH Infections in Children
}

\author{
Sanjoy Kanti Biswas ${ }^{*}$ \\ Md. Badruddoza ${ }^{2}$ \\ Nahid Sultana ${ }^{1}$ \\ 'Department of Microbiology \\ Chattagram Maa-O-Shishu Hospital Medical College \\ Chittagong, Bangladesh. \\ ${ }^{2}$ Department of Paediatrics \\ Chattagram Maa-O-Shishu Hospital Medical College \\ Chittagong, Bangladesh.
}

*Correspondence to:

\section{Dr. Sanjoy Kanti Biswas}

Associate Professor

Department of Microbiology

Chattagram Maa-O-Shishu Hospital Medical College

Chittagong, Bangladesh.

Mobile : +88 01715639017

Email:sanjoyustc@gmail.com

www.banglajol.info/index.php/CMOSHMCJ

\begin{abstract}
Background : The acronym "TORCH" was introduced to highlight a group of pathogens that cause a congenital and perinatal infections: Toxoplasma gondi, rubella virus, Cytomegalovirus (CMV) and Herpes Simplex Virus (HSV). These pathogens are often associated with congenital anomalies. Congenital malformations have a direct impact on the family. This study was undertaken to detect the serological evidence of TORCH infections in children, by establishing the presence of specific IgM antibodies. Methods: During the period $1^{\text {st }}$ June 2016 to $30^{\text {th }}$ May 2017, 58 suspected TORCH infection cases were included from Paediatrics Department of CMOSH for TORCH antibody detection. The children were in the age of 0 day to 1 year with an average age of $3.3 \pm 2.59$ months. The serum samples were tested forlgM and $\mathrm{IgG}$ antibodies against TORCH agents by using enzyme linked immunoassay method (ELISA). Results: Among the 58 children, seropositivity was found in $55(94.82 \%)$ cases. Of the 55 seropositive cases serological evidence for combination of $\operatorname{IgM}$ and $\operatorname{IgG}$ with any one of the TORCH agents was detected in $25(43.10 \%)$ and IgG alone was detected in $30(51.72 \%)$ children. IgM/IgG antibody positivity to Toxoplasma, Rubella, CMV and HSV was $21(36.21 \%), 50(86.21 \%), 52(89.66 \%)$ and $8(13.79 \%)$ respectively. IgM anti-CMV were observed in highest number of cases $19(32.76 \%)$, followed by IgM anti-rubella 7(12.07\%). IgM against HSV and Toxoplasma were found in equal number of cases, 3(5.17\%) each. Conclusions: Awareness amongst clinicians and mothers about TORCH infections and their consequences should be developed.
\end{abstract}

Key words: TORCH; Seropositivity; ELISA.

\section{INTRODUCTION}

The acronym "TORCH" was introduced by Nahmias in 1971 to highlight a group of pathogens that cause a congenital and perinatal infections leading to fetal and neonatal morbidity and mortality: Toxoplasma gondi, rubella virus, Cytomegalovirus (CMV) and herpes simplex virus ${ }^{1,2}$. These pathogens usually cause only asymptomatic or mild infections in mother, but can cause much more serious consequences in fetus ${ }^{3}$. Congenital malformations caused by these pathogens are important causes of morbidity, mortality and disability and are found in approximately $2 \%-3 \%$ of neonates. Congenital malformations have a direct impact on the family and place a financial burden on medical, educational and support services ${ }^{4}$. This acronym was proposed to simplify diagnostic procedures in severely ill children and to impose clearer structure in the large differential diagnosis of congenital infections ${ }^{1}$. 
The prozoan parasite Toxoplasma gondi can cause infection when its oocyst or tissuecyst are ingested. Primary infection in pregnancy has been associated with spontaneous abortion and still birth $^{5}$. The highest risk of giving birth to a child with congenital toxoplasmosis is about $10 \%$. Most children develop normally, but about $20 \%$ develop sequale. Congenital toxoplasmosis may result in retinochoroiditis and retinal scarring in $12 \%$ of children and neurological abnormalities in about $12 \%-16 \%$ cases $^{1}$. Large variation in seroprevalence may exit due to differences in climate; cultural differences in amount of raw meat consumed, and increased consumption of meat from animals firmed outdoors and frozen meat ${ }^{5}$.

Rubella virus is a member of togavirus family which is transmitted by direct droplet contact from nasopharyngeal secretions, replicate in the lymphoid tissue of upper respiratory tract and spreads hematogenously. The virus can infect and replicate in the placenta of pregnant women. The devastating consequences of rubella infection during pregnancy are abortion, still birth andfetal malformation that arise from maternal infection during the first trimester of pregnancy ${ }^{6}$. Rubella is a mild viral illness in children but can occasionally infect adults. $10 \%-20 \%$ of women of child bearing age are susceptible to rubella. WHO estimates that, worldwide, more than one lakh children are born with congenital rubella syndrome each year, most of them in developing countries ${ }^{3}$. Annual number of reported rubella cases in Bangladesh was 13,464 in 2009 and 13,125 in 2010 and rubella attack rate among antenatal population in Bangladesh is 14.5 in 1000 during pregnancy ${ }^{6}$.

CMV is the most common cause of congenital infection and its incidence has been estimated to be between $0.2-2.2 \%$ of all live births in different parts of the world. In Malaysia the incidence of CMV was detected in $11.4 \%$ infants $^{7}$. Primary CMV infection in pregnancy has a higher incidence of symptomatic congenital infection and fetal loss. The transmission of CMV infection to fetus occurs in $40 \%$ of cases of primary infection and results in the delivery of $10-15 \%$ symptomatic and $85-90 \%$ asymptomatic congenitally infected newborns ${ }^{3}$.

Although HSV can be vertically transmitted during pregnancy, this is extremely rare. Neonatal disease is the result of perinatal transmission ${ }^{1}$. Of all the children born with neonatal HSV infection, $60 \%-80 \%$ of mothers are asymptomatic for the disease. True primary infection has the highest risk of transmission, about $50 \%{ }^{8}$. This is probably due to high viral load and longer period of viral shedding in the mother. Reactivation of latent infection has the lowest risk for maternal fetal transmission $(2 \%)$. The incidence of herpes neonatoram varies between 31 in 100000 live births in USA, 3.2 per 100000 live births in Netherland and 1.65 per 100000 live births in UK.Seroprevalence varies greatly and is associated with geographic regions, sex, age, race and high risk behaviours ${ }^{1}$. Localized congenital HSV infection is limited to the skin, eye or mouth, whereas CNS disease results in encephalitis and disseminated disease leads to multiple organ involvement ${ }^{8}$.
Many sensitive and specific tests are available for serological diagnosis of TORCH agents. Complex ELISA test for IgM/ IgG antibodies are highly sensitive and specific ${ }^{4}$. Interpretation of serology for congenital infections should be done with care. $\operatorname{IgM}$ is fetally derived and a positive IgM is indicative of fetal infection. IgG, in contrast, can cross the placenta and is maternal in origin. Therefore in the absence of fetal infection neonatal IgGtitres will fall after birth ${ }^{1}$.

Due to lack of national screening program, there is no baseline serological data regarding the presence of anti-torch antibody in neonates. This study was undertaken to detect the serological evidence of TORCH infections in neonates, by establishing the presence of specific IgM antibodies.

\section{MATERIALS AND METHODS}

During the period $1^{\text {st }}$ June 2016 to $30^{\text {th }}$ May 2017, 58 suspected TORCH infection cases were referred to the Microbiology Laboratory from Pediatrics Department of Chattagram Maa-OShishu Hospital (CMOSH) for TORCH antibody detection. The children were in the age group of 0 day to 1 yearwith an average age of $3.3 \pm 2.59$ months. Approval was taken properly from Chattagram Maa-O-Shishu Hospital Medical College (CMOSHMC) ethical committee.

Blood samples received from all the cases were clotted and centrifuged for serum separation prior to testing. All the sera were stored at $-20^{\circ} \mathrm{C}$ till tested.The serum samples were tested for IgM and IgG antibodies against Toxoplasma, CMV, Rubella virus and Herpes simplex virus using enzyme immunoassay method (ELISA) for quantitative detection. Kit instructions were strictly adhered to while processing the samples. Interpretation of the results was based on controls provided with the kit. Test sample was said to be positive when its absorbance value was higher than the absorbance value of cut-off control.

\section{RESULTS}

This study included 58 children ranging from 0 day to 1 year of age. Seropositivity were found in $55(94.82 \%)$ and Seronegativity to IgM/IgG was observed in $3(5.18 \%)$ cases. Among seropositive cases serological evidence for combination of $\operatorname{IgM}$ and $\mathrm{IgG}$ with any one of the TORCH agents was detected in 25 $(43.10 \%)$ and $\operatorname{IgG}$ alone was detected in $30(51.72 \%)$ children (Table-1).

Table 1 : Serological distribution of study population $(n=58)$

\begin{tabular}{llc} 
& No. & Percentage (\%) \\
IgM+IgGpositve & 25 & 43.10 \\
IgG positive & 30 & 51.72 \\
Negative & 03 & 5.18 \\
Total & 58 & 100 \\
\hline
\end{tabular}

IgM/IgG antibody positivity to Cytomegalovirus was $52(89.66 \%)$ followed by seropositivity against Rubella infection 52(89.66\%). IgM/IgG antibody positivity to Toxoplasma and Herpes virus was $21(36.21 \%)$ and $8(13.79 \%)$ respectively (Table-II). 
Table 2 : Seropositivity distribution of TORCH specific antibodies in the study population $(\mathrm{n}=58)$

\begin{tabular}{|c|c|c|c|c|}
\hline \multirow[t]{2}{*}{ Test } & \multicolumn{2}{|c|}{ Seropositive } & \multicolumn{2}{|c|}{ Seronegative } \\
\hline & No. & $\begin{array}{l}\text { Percentage } \\
(\%)\end{array}$ & No. & $\begin{array}{l}\text { percentage } \\
(\%)\end{array}$ \\
\hline $\begin{array}{l}\text { Toxoplasma } \\
\text { gondi }\end{array}$ & 21 & $36.21 \%$ & 37 & $63.79 \%$ \\
\hline Rubella virus & 50 & $86.21 \%$ & 08 & $13.79 \%$ \\
\hline Cytomegalovirus & 52 & $89.66 \%$ & 06 & $10.36 \%$ \\
\hline $\begin{array}{l}\text { Herpes simplex } \\
\text { virus }\end{array}$ & 08 & $13.79 \%$ & 50 & $86.21 \%$ \\
\hline
\end{tabular}

Distribution of specific IgM and IgG antibodies of TORCH agents has been shown in table-3. Amongst them highest number IgM positive cases were observed in Cytomegalovirus infection 19(32.76\%) followed by Rubella 7(12.07) \%.IgM positivity against HSV and Toxoplasma were $3(5.17 \%)$ and $3(5.17 \%)$ respectively.

Table 3 : Distribution of TORCH specific IgM and IgG in the study population $(\mathrm{n}=58)$

\begin{tabular}{|c|c|c|c|c|}
\hline \multirow{2}{*}{ Antibody type } & \multirow[b]{2}{*}{ No. } & \multirow{2}{*}{$\begin{array}{l}\text { IgM } \\
\text { Percentage } \\
(\%)\end{array}$} & \multicolumn{2}{|c|}{ IgG } \\
\hline & & & No. & $\begin{array}{l}\text { Percentage } \\
(\%)\end{array}$ \\
\hline Toxoplasma gondi & 03 & $5.17 \%$ & 18 & $31.03 \%$ \\
\hline Rubella virus & 07 & $12.07 \%$ & 43 & $74.14 \%$ \\
\hline Cytomegalo virus & 19 & $32.76 \%$ & 33 & $56.90 \%$ \\
\hline $\begin{array}{l}\text { Herpes simplex } \\
\text { virus }\end{array}$ & 03 & $5.17 \%$ & 05 & $8.62 \%$ \\
\hline
\end{tabular}

The number of seropositivity for IgM antibodies against Toxoplasma, Rubella, CMV and HSV either as a single organism or in combination were observed in 25 (45.45\%) cases. It was observed that IgM antibody positivity was highest for CMV 13(52\%) followed by Rubella and HSV in 3(12\%) cases each. No cases were infected by Toxoplasma alone. Mixed infections were observed in 6(24\%) cases (Table-4).

Table 4 : Prevalence of IgM Seropositivity of TORCH either alone or in combination

\begin{tabular}{lr}
$\begin{array}{l}\text { IgM for single/ } \\
\text { combination of } \\
\text { organism }\end{array}$ & $\begin{array}{c}\text { No. of positive } \\
\text { cases }(\%)\end{array}$ \\
Toxoplasma & $00(0.0)$ \\
Rubella & $03(12.00)$ \\
CMV & $13(52.0)$ \\
HSV & $03(12.0)$ \\
Rubella and CMV & $03(12.0)$ \\
Toxoplasma and CMV & $02(8.0)$ \\
Toxoplasma,Rubella and CMV & $01(4.0)$ \\
Total & $25(100)$ \\
\hline
\end{tabular}

\section{DISCUSSION}

This study was done to evaluate the TORCH infections in children admitted to a tertiary level hospital (CMOSH) of Chittagong, Bangladesh.

Any patient infected with TORCH group of agents, mainly two types of antibodies ( $\operatorname{IgM} \& \operatorname{IgG}$ ) are produced against the infecting organisms. By measuring the antibodies we can identify the type of infection. When IgM antibody is present, it invariably suggests acute/recent infection and the presence of IgG suggests past or present active infection ${ }^{9}$. WHO and CDC recommended confirmation of congenital TORCH infection by detection of specific IgM in blood and persistence of IgGtitres over time, i.e no decline in titre as expected for transplacentally derived maternal IgG (By 6 monthes) ${ }^{10}$.

In the present study, an attempt was made to assess the seroprevalence of TORCH specific antibodies in children on the basis of detection of IgM and/or IgG antibodies. The overall prevalence of seropositivity found in this study was $94.82 \%$ and seronegative cases were $5.18 \%$. A study in India by padmavathy $\mathrm{M}$ et al showed only $1.1 \%$ seronegativity ${ }^{3}$.

The seroprevalence of CMV (89.66\%) presented in this study is similar to a study done by Neirukh et al. in Palestine which is $88 \%$ and Nahla et al in Sudan showd $94.3 \%$ seropositivity ${ }^{11,7}$. In this study $\mathrm{IgM} / \mathrm{IgG}$ seropositivity against Rubella was $86.21 \%$, is similar to a study done by Nazme et al. at Dhaka Shishu hospital which is $88 \%{ }^{6}$. Golalipour et al. in Iran reported antiTox antibody in $35.9 \%$ neonates which correlates with the findings $(36.21 \%)$ of present study ${ }^{4}$. Herpes simplex seropositivity reported in this study was $13.79 \%$, similarly Bin Lu et al in China demonstrated $17.30 \%$ anti HSV antibody ${ }^{11}$. But Golalipour et al in Iran showed no anti HSV antibody ${ }^{4}$. This difference is likely due to geographical differences in the prevalence of HSV.

In this study CMV specific IgM was $36.5 \%$ which is almost similar to a study done by Bin Lu et al in China who presented $27.5 \%$ IgM seropositivity ${ }^{11}$. But Inderjeet Gandhoke et al in India presented $18.75 \%$ IgM seropositivity ${ }^{12}$. Tahari Neirukh et al in Palestine showed $13.7 \%$ IgM anti $\mathrm{CMV}^{13}$. This may be due to differences in geographical locations and socioeconomic status.

In our study seroprevalence of rubella specific IgM was $14 \%$, similarly Mirambo et al. in Tanzania reported $10.9 \%$ rubella specific IgM and Chandy et al from Vellore, India reported 9.4\% IgM positive cases ${ }^{14,10}$. Nazme et al from Dhaka Shishu hospital reported $28 \%$ children were seropositive for rubella IgM among suspected congenital rubella syndrome cases ${ }^{6}$.

In this study Toxoplasma specific IgM was $5.17 \%$ which correlates with the findings of Golalipour et al in Iran. They repoted 3.2\% IgM anti Tox antibody ${ }^{4}$. But in this study no cases were infected by Toxoplasma gondi alone. In this study IgM anti HSV was $5.17 \%$ which is almost similar to the findings demonstrated by Bin lu et al in China, $2.80 \%{ }^{11}$.

Mixed infection were found in $24 \%$ cases which is similarly $\mathrm{M}$ Padmavathy et al,. showed mixed infection in $32 \%$ cases $^{3}$. 


\section{CONCLUSIONS}

This study showed a high prevalence of infections caused by TORCH complex amongst children. Therefore serological testing of both mothers and children could be useful.

\section{RECOMMENDATIONS}

- In children TORCH infection causes high mortality and morbidity. So a long term broad based study is required.

- TORCH testing should not be regarded as single serum testing.Serial specimens demonstrating a sustained titre of IgG would provide further confirmation of TORCH infections.

- All pregnant women should be routinely screened for TORCH agents at the first antenatal visit.
- Development and introduction of vaccine against TORCH agents is essential and vaccinating children and childbearingaged women with available vaccine is important.

- Awareness amongst clinicians and patients about TORCH infections and their consequences should be developed.

\section{DISCLOSURE}

All the authors declared no competing interest.

\section{REFERENCES}

1. De Jong Ep,Vossen ACTM, Walther FJ, Lopriore E. How to use neonatal TORCH testing. Arch dis child Educpract Ed. 2013;98:93-98.

2. Tian C, Ali AS, Weitkamp JH. Congenital infections, Part 1: Cytomegalovirus, Toxoplasma, Rubella and Herplex Simplex. Neo Reviews. $2010 ; 11(8)$

3. Padmavathy M, Goweri M, Malini J, Umapthy BL, Navaneet BV, Bhatia M, Harle S. Seroprevalence of TORCH infections and adverse reproductive outcome in current pregnancy with bad obstetric history. J clin biomed sci. 2013; 3(2):62-71.

4. Golalipour MJ, Khodabakhshi B, Ghaemi E. Possible role of TORCH agents in congenital malformations in Gorgan, northern Islamic Republic of Iran. Eastern Medi. Health J. 2009;15 (2).

5. Cook AJ, Gilbert RE, Buffolano W. Sources of toxoplasma infection in pregnant women: European multicentre case-control study. European Research Network on Congenital Toxoplasmosis. BMJ. 2000;321:142-147.

6. Nazme NI, Houque MM, Hussain M. Congenital Rubella Syndrome: An overview of clinical presentations in Bangladeshi children. Delta Med Col J. 2014;2(2): $42-47$.

7. NahlaKh.M, Ali Y.H ,Enan K.A. Studies on congenital infections in infants in Sudan: Seroprevalence of Cytomegalovirus. J. of Science and Technology. 2011; 12(4):82-90.

8. Remington JS, Klein JO, Wilson CB. Infectious diseases of the fetus and newborn. 7th edn. Philadelphia, USA:Elsevier Saunders. 2007.

9. Nabi SN, Wasey AFSA, Haider KMTS, Khan AA, Houque MM. Seroprevalence of Torch antibody in pregnant women. J. AFMC Bangladesh. 2012;8(1):35-39.

10. Chandy S, Abraham AM, Jana AK, Agarwal I, Kekre A, Korula G, Selvaraj K and Muliyil JP. Congenital rubella syndrome and rubella in Vellore, South India. J. Epidemiol. Infect. 2011; 139: 961-966.

11. Lu B, Yang Y. Detection of TORCH pathogens in children with congenital cataracts. J. experimental and therapeutic medicine. 2016;12: 1159-1164.

12. Gandhoke I, Aggarwal R, Lal S and Khare S. Congenital CMV infection in symptomatic infants in Delhi and surrounding areas. Indian J. pediatrics. 2006; 73: 1095-1097.

13. Neirukh T, Qaisi A, Saleh N, Rmaileh AA, Zahriyeh EA, Qurei L, Dajani F, Nusseibeh T, Baraghiti S and Azzeh M. Seroprevalence of Cytomegalovirus among pregnant women and hospitalized children in Palestine. BMC Infectious Diseases. 2013; 13: 528.

14. Mirambo MM, Aboud S, Mushi MF, Seugendo M, Majigo M, Gorb U, Mshana SE. Serological evidence of acute rubella infection among under fives in Mwanza: A threat to increasing rates of congenital rubella syndrome in Tanzania. Italian J. pediatrics. 2016; $42: 54$ 